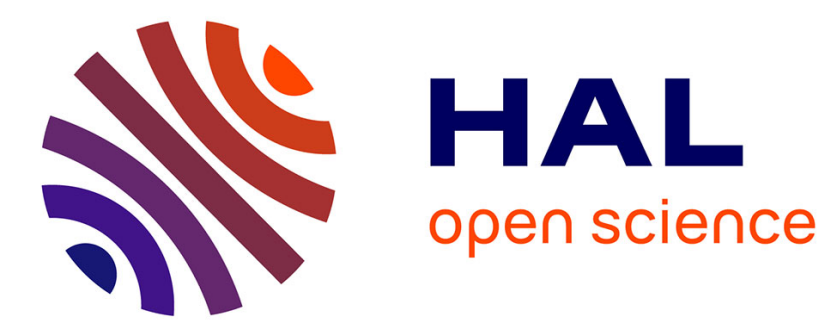

\title{
Digital Social Learning - How to Enhance Serious Gaming for Collaborative Networks
}

\author{
Christian Zinke, Julia Friedrich
}

\section{To cite this version:}

Christian Zinke, Julia Friedrich. Digital Social Learning - How to Enhance Serious Gaming for Collaborative Networks. 18th Working Conference on Virtual Enterprises (PROVE), Sep 2017, Vicenza, Italy. pp.669-677, 10.1007/978-3-319-65151-4_59 . hal-01674898

\section{HAL Id: hal-01674898 \\ https://hal.inria.fr/hal-01674898}

Submitted on 3 Jan 2018

HAL is a multi-disciplinary open access archive for the deposit and dissemination of scientific research documents, whether they are published or not. The documents may come from teaching and research institutions in France or abroad, or from public or private research centers.
L'archive ouverte pluridisciplinaire HAL, est destinée au dépôt et à la diffusion de documents scientifiques de niveau recherche, publiés ou non, émanant des établissements d'enseignement et de recherche français ou étrangers, des laboratoires publics ou privés. 


\title{
Digital Social Learning - How to Enhance Serious Gaming for Collaborative Networks
}

\author{
Christian Zinke and Julia Friedrich \\ Institute for Applied Informatics e.V., \\ Leipzig, Germany \\ \{zinke, friedrich\}@infai.org
}

\begin{abstract}
Virtual organizations and enterprises are prominent examples for collaborative networks $(\mathrm{CN})$. Trends like Web 2.0 and Social Media refine the technological base of CN, namely through enterprise social networks (ESN). To strengthen knowledge management and through it the innovation capabilities of $\mathrm{CN}$, further research on supporting knowledge exchange and social learning within ESN is needed. Approaches like serious gaming or digital social learning already tackle this problem. However, there is still a significant lack in integrated approaches, concepts or tools for ESN and digital social learning. In order to address this issue, within the work presented in this paper a design research approach has been chosen to consider the lack of methodological clearness of the iteration process. Thus, the paper will firstly introduce a framework for the iteration process of design research and secondly show first insights on how to integrate ESN and digital social learning.
\end{abstract}

Keywords: Digital Social Learning, Enterprise Social Network, Collaborative Network, Design Research.

\section{Introduction}

An important driver for collaborative networks $(\mathrm{CN})$ is the digitalization, based amongst others on the rise of computer networks. The forms of $\mathrm{CN}$ that can be distinguished are virtual organizations, virtual enterprises or collaborative laboratories [1]. $\mathrm{CN}$ in that respect are to be defined as an "alliance constituted by a variety of entities (e.g. organizations and people)" [2]. These entities are spread out over a multitude of domains. In general, they are independent, geographically distributed and vary in their culture and their goals $[1,2]$. Further, $\mathrm{CN}$ enable a better objective attainment for all stakeholders. One key factor for establishing successful $\mathrm{CN}$ is the handling of knowledge, especially its exchange and management [3]. Web 2.0, social media and networks enable a novel technical basis for $\mathrm{CN}$ termed enterprise social networks (ESN). Amongst others, important functions of ESN are knowledge sharing, learning as well as training by means of exercises and document sharing $[4,5]$. Knowledge management and social learning as an integrated element of human resource development in ESN have already been developed and are field tested in small scale settings [6]. In order to strengthen knowledge management in $\mathrm{CN}$, more 
research addressing barriers as well as motivation for knowledge exchange within ESN, considering social as well as personal needs and demands, is required. However, some serious game approaches almost address learning and explicit knowledge exchange within virtual groups and teams. While in the private sector some social networks do already have social games implemented, on enterprise and $\mathrm{CN}$ level this is a new ground, especially serious game implementation. Up to now, both worlds - digital social learning (DSL) by means of serious gaming and ESN are side by side when it comes to the lack of integrated considerations or designs combining them. This paper presents research in process with the aim of bridging the gap between DSL and ESN with the special consideration of employee's needs and requirements.

This is not only a thematically, but also a methodological challenge. As there already are approaches for serious gaming and ESN, the chosen design research approach does not start on green fields. So far, an artefact, in our case the serious game Yeepa, has been implemented and elaborated in various fields. The problem is a lack of methodological clarity of the design research process in such cases - starting with elaboration of an artefact to develop requirements for a new one. To sum up, the paper will contribute by developing a methodological design research procedure, focusing on the iteration process. Therefore, a framework to classify evaluation results will be presented. The method will be used exemplarily to develop problem descriptions and detailed requirements for linking DSL and ESN.

\section{Methodology}

The methodology chosen is use case driven and conducted within the design research approach (especially for Information Systems - IS). Design Science Research (DSR) can be described as a constructive research paradigm [7] focusing on the design and evaluation of artefacts. These artefacts are designed to solve human problems [8]. To do so, Peffers developed four main steps (see [9]), firstly, the problem has to be described and analyzed, secondly the objective has to be set, thirdly, the artefact needs to be designed and developed and fourthly, the impact of the artefact will be evaluated. While some authors differ as to the granularity of the research process [7, 10], they agree in principle to the iterative character of the methodology. Research conducted within design science does often focus on problem descriptions, designing and implementing artefacts, while the evaluation process is often performed poorly [11]. Thus, common models of design research cycle easily link the evaluation results to the problem description (e.g [12-15]). This approach implies an easy way to match problems, requirements, design objects and impacts of the artefact, but research works with one or more iterations are very rare. The problem is that design research is an explorative approach, where even solved problems may cause novel ones. In order to strengthen the evaluation and iteration of the design research approach, the presented paper will focus methodologically on the evaluation and the transition to an enhanced problem description for an improved design. Fig. 1 illustrates the adapted approach of the paper. 


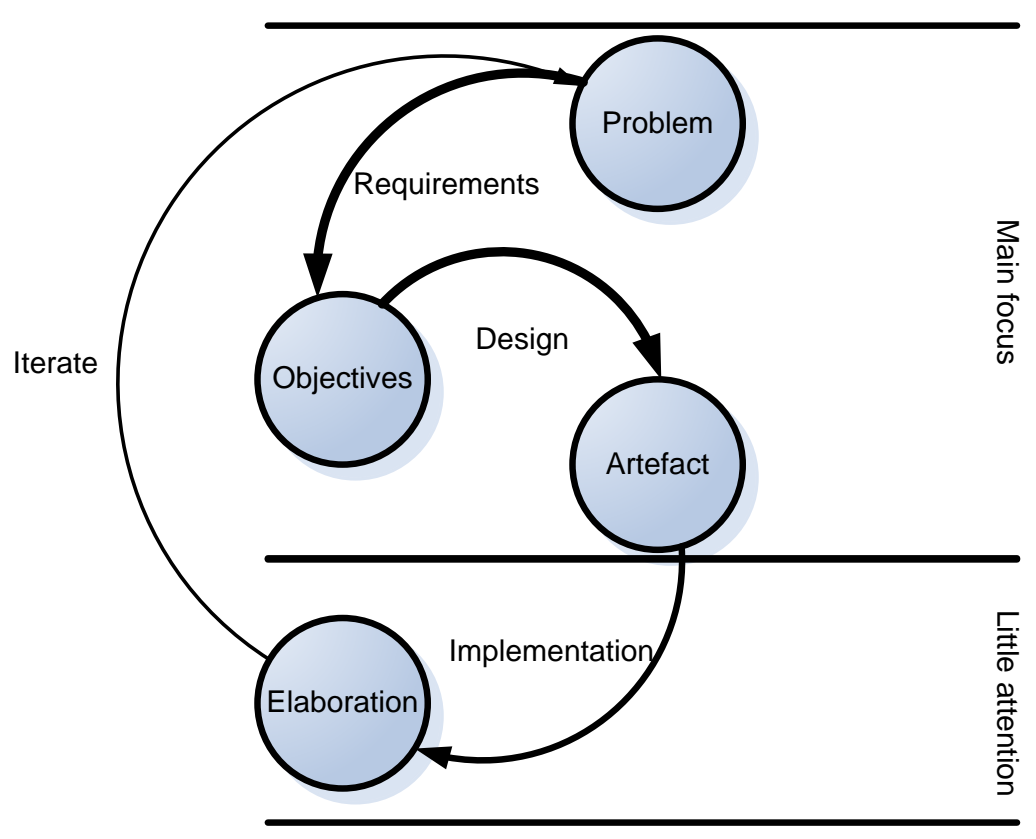

Fig. 1. Design research process

In order to do so, five cases of the iteration process can be described (see also Table 1).

I. Artefact does fulfill the given requirements. (most cases, e.g. [15])

II. Artefact does not fulfill effectively its role, elaboration results show that artefact does not have intended use.

Problem and requirements are the same. The design of the artefact has to be improved.

III. The artefact causes unintended consequences.

The original problem is solved, but novel problems raise up because of the artefact. This leads to extended problem descriptions and requirements.

IV. Elaboration results show goal attainment, but for some reasons the conditions are changing, which lead to an ineffective artefact.

Novel conditions (e.g. technologies or legal boundaries) lead to rethinking and adjust the problems and requirements.

V. Elaboration results show goal attainment and artefact may be suitable for other contexts.

Successful solutions need to be transferred and re-innovated in new context. Development of novel problem description and requirements based on evaluation and cross-cases analysis [16] is needed. 
Table 1. Design research iteration framework

$\begin{array}{cll} & \text { Impact on problem and requirements } & \text { Impact on design } \\ \text { I } & \text { None } & \text { None } \\ \text { II } & \text { None } & \text { Adjust } \\ \text { III } & \text { Extension } & \text { Extension } \\ \text { IV } & \text { Adjust } & \text { Re-new } \\ \text { V } & \text { New } & \text { Re-new }\end{array}$

The following work focusses on case $\mathrm{V}$, where a successful solution needs to be evaluated and analyzed in order to transfer it into other contexts. However, Pries-Heje et al. [11] developed a framework to classify the evaluation. According to this classification, the presented use case is ex post and naturalistic, which means that an artefact is existing and tested in real environments. Further, the presented example concentrates on the process which is supported by the artefact [11].

\section{Related Work}

ESN or Enterprise 2.0 denotes the usage and adaption of Web 2.0 paradigms and especially Social Media techniques [17-19]. These are used to support the transformation towards virtual organisations or social business, which is defined as the "application of social computing to enterprise challenges" [20]. ESN supports the $\mathrm{CN}$ to accomplish their aims by supporting work-related goals and communication $[21,22]$. One of the many functions is the support of knowledge exchange and learning [4]. While a lot of existing work concentrates on traditional Web 2.0 technologies (such as blogs and tags) to realise ESN functions [23-25], examples of explicit knowledge exchange is rarely considered. In addition to ESN, one concept for implementing explicit knowledge transmission and training is serious gaming.

The concept of serious gaming is the conjunction of game mechanics and design with a learning approach [26]. It combines playful elements with serious content, skill improvement through repetition and excitement [27]. Due to the fact that the repetition of content is embedded in a playful and challenging experience, learning is performed automatically while the focus of the user is on the enjoyment and challenge. There is a large variety of possibilities for serious game design. Wellknown examples are the flight simulator, learning software or applications for mental fitness. Typically adopted game mechanics are shown in Fig. 2. 

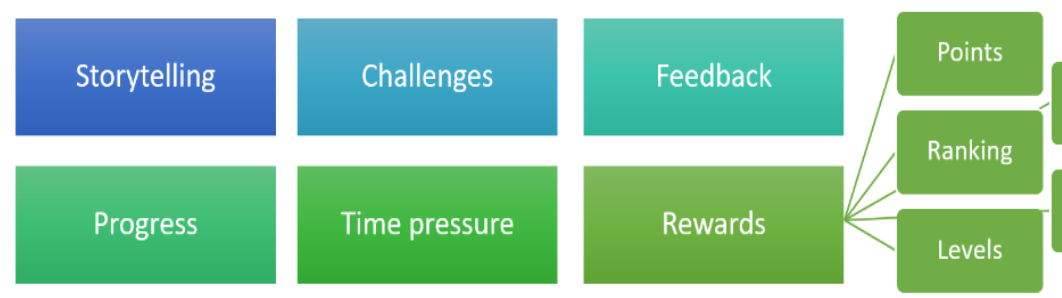

Status

Fig. 2 Serious game mechanism [28]

In the following, with regard to the use case, we will focus on challenges, feedback and progression. Playing a game confronts the player with a certain uncertainty and suspense. The mastering of tasks in increasing levels of difficulty pose a challenge for users. The intrinsic motivation, especially of ambitious players but also of those players with a weak ambition, is affected by cognitive challenges. Feedback, which is bounded to the need for recognition, is another motivating mechanism. Other than challenge, feedback is affecting the extrinsic motivation. It enables the recipient to reflect and contextualize its own work. This way, feedback supports the learning progress and motivates the player at the same time. Progression, too, is supporting the reflection of performance. Progression in serious games can be adapted in different contexts. On the one hand, it may be used in form of a progress bar which shows the achieved but also the forthcoming efforts. On the other hand, it can be applied in form of a curve that illustrates skill improvements and achieved mile stones. This way, gaming mechanisms like feedback and progress impart a feeling of competence and positively affect self-reported learning outcomes [29]. All three components, challenge, progression and feedback, positively affect users motivation and are therefore appropriate mechanics for Serious Game in a corporate context.

\section{Use Case}

Yeepa is a serious gaming solution designed to create an innovative digital learning approach, which allows for an integration of a group level instead of focusing on the individual player only. The key element of Yeepa is a quiz. The players are answering multiple choice questions individually, however, the analysation is done on a group basis - with direct feedback after every game - including supervision to improve players' knowledge. The playful quiz atmosphere promotes motivation by creating fun and challenge which may lead to a will to repetition. Every repetition leads to progression. In order to evaluate the benefits users derive by playing Yeepa, the solution has been implemented into two settings. In context of the German national IT summit, school kids on the one hand and IT-experts on the other hand were invited to play Yeepa, answering questions about online safety and data security. Within a defined time frame of one week altogether 4000 pupils played a pool of 160 questions taken from ECDL (European Computer Driving License). On the whole, 400.000 questions where played which allowed for a psychometric calibration by using the 
Rasch model [30]. This way, 43 questions/items with a valid balance of knowledge competence and probability of success could be identified. These questions built the basis for the Yeepa game, played by IT-experts during the IT summit.

The results of all players where analyzed by use of the so-called Yeepa Index. Next to the probability of success, validated on basis of a psychometric analysis, the Yeepa Index calculates with a score that weights the degree of difficulty of every item. The Yeepa Index allows for a comparison of results within and between groups and topics. Additionally, progression analysis with regard to time can be done.

The surprising result that every category was dominated by the pupils, strengthens the argument of knowledge progression through repetition, because the pupils got much more time to improve their knowledge (pupils more than one week, IT experts only one day). Further the result shows the impact of digital social learning. These results do not directly lead to obvious problems in order to start the next loop of design research. Therefore, we analyzed the different settings, including the new one, where Yeepa should be implemented, as a cross case analysis (see Table 2) [16]. Part of the analysis is the comparison of network type of the implementation setting. The topology of network type originate from computer science [31], but can be also be applied for the social game setting. Next we will describe the most important in short. Mesh networks are networks, where every system user is directly connected to another user, so everybody know each other. A star network is a network, where all participants are connected to one central hub (the initiator), and do not know each other. A hierarchical network have multiple groups connected to one hub, these hubs can also be connected to a subordinated hub. All of these network types have implications on knowledge transfer and social embedment. While "hub-based" network needs a coordination of the knowledge through this hub (increased control mechanisms), mesh networks can share and distribute knowledge much more independently (less control possible).

Table 2 Cross-case analysis serious gaming in enterprises

\begin{tabular}{l|lll}
\multicolumn{2}{l}{ SCHOOL } & SUMMIT & ENTERPRISE \\
\hline $\begin{array}{l}\text { NETWORK } \\
\text { TYPE }\end{array}$ & $\begin{array}{l}\text { mesh } \\
\text { networks } \\
\text { ORIGIN }\end{array}$ & $\begin{array}{l}\text { no or star } \\
\text { network } \\
\text { randomized }\end{array}$ & $\begin{array}{l}\text { hierarchical or mesh } \\
\text { networks } \\
\text { project or departments }\end{array}$ \\
$\begin{array}{l}\text { FOCUWORK } \\
\text { GAME FOCUS }\end{array}$ & learning & exploring & business \\
$\begin{array}{l}\text { INTERACTION } \\
\text { RATE }\end{array}$ & instruction & fun & high \\
THEMES & raw & $\begin{array}{l}\text { instruction } \\
\text { high }\end{array}$ \\
GUIDANCE & static theme & static theme & $\begin{array}{l}\text { dynamic themes } \\
\text { teacher }\end{array}$ \\
& & administrator & $\begin{array}{l}\text { supervisor, cross-domain or } \\
\text { intergenerational expert }\end{array}$
\end{tabular}

The network type is very important, because motivation comes not only from the challenge, it is also about social embedment of the challenge - the networking origin. Further, the interaction rate may support the will for repetition. While in school, social group-based and highly interactive mesh networks created good results, the 
randomized networks or little star networks on the IT summit with very raw interactions had problems to keep up. Another important difference between the given settings and enterprises are the themes. While in school and on summit, the theme was static given by an administrator, knowledge exchange in enterprises is highly dynamic - given by supervisors, cross-domain and intergenerational experts.

Now we got a clear vision of what the digital social gaming tool Yeepa can handle. Knowledge creation within social group-based networks which concentrate on learning, with a high interaction rate and static themes set by an administrator, seems to be a very fruitful setting. In contrast, a randomized setting, including no networks or small star networks, with raw interactions, where the actors focus on other things, are not very sufficient. Changing the conditions means to change the impact of the artefact. Analysis of the conditions leads to a problem description and first requirements for an artefact of digital social learning as part of the ESN:

1. How to strengthen motivation of hierarchical or star-networks?

2. How to combine network focus and serious gaming in order to enhance motivation for knowledge exchange and training?

3. How to implement dynamic themes within the given context (1\&2)?

The motivation and the willingness to repetition of the employee are the key factors for a successful learning. Also, social distance in hierarchical or star-networks which is quite higher than in mesh networks seems to be an important factor of motivation ${ }^{1}$. Further, compatibility of employee's needs, business goals and gaming theme need more consideration in order to apply the solution within ESN. While, Yeepa already supports the user in the generation of new content, so far, the corresponding process is time-consuming and not compatible with daily business. Thus, the main problem, we may focus on is the knowledge creation process in Yeepa within ESN.

\section{Summary and Further Work}

The paper concludes with two major results. Firstly, (1) we focus on methodological clearness on design research iteration. Thus, we developed a framework, which describes the main cases and their impacts on the research process. The developed framework can be used as a guide for further iterations and the assessment of the impact of the elaboration. Further work is needed to include this framework into common evaluation methods as well as to establish novel methods which support the presented framework. With the help of this foundational description, we implement, secondly, (2) this process in order to develop novel problem descriptions, research questions and goals for adapting serious gaming into ESN as a foundation $\mathrm{CN}$. The main contributions of the paper are the developed problem specifications and requirements for an artefact of digital social learning as part of the ESN. This work is only the starting point for adapting Yeepa to ESN contexts and evaluate its impacts.

\footnotetext{
${ }^{1}$ Here anonymization have contradiction results, in supporting and weaken motivation.
} 
Therefore, new models and artefacts are needed, which will be developed next - such as a knowledge discovering tools and ESN adapter.

Acknowledgement: The German Federal Ministry of Education and Research have funded the work leading to this publication under grant number 02L15A070 (Project: SB:Digital). Furthermore, the article is based on the results of the joint research project "MACKMA" which was funded by the German Ministry of Education and Research (Grant Number: 01IS15057C) under the supervision of the PT-DLR. The authors thank for the funding.

\section{References}

1. Camarinha-Matos, L.M., Afsarmanesh, H.: Collaborative networks: A new scientific discipline. J Intell Manuf (2005), 16(4-5): 439-452. doi: 10.1007/s10845-005-1656-3

2. Camarinha-Matos, L.M., Afsarmanesh, H.: On reference models for collaborative networked organizations. International Journal of Production Research (2008), 46(9): 2453-2469. doi: 10.1080/00207540701737666

3. Allee, V.: RECONFIGURING THE VALUE NETWORK. Journal of Business Strategy (2000). doi: 10.1108/eb040103

4. Turban, E., Bolloju, N., Liang, T.-P.: Enterprise Social Networking. Opportunities, Adoption, and Risk Mitigation. Journal of Organizational Computing and Electronic Commerce (2011). doi: 10.1080/10919392.2011.590109

5. Cormican, K., Dooley, L.: Knowledge Sharing in a Collaborative Networked Environment. J. Info. Know. Mgmt. (2007). doi: 10.1142/S0219649207001706

6. Fulk, J., Yuan, Y.C.: Location, motivation, and social capitalization via enterprise social networking. Journal of Computer-Mediated Communication 19(1), 20-37 (2013)

7. Baskerville, R., Pries-Heje, J., Venable, J.: Soft design science methodology. In: Vaishanvi, V., Purao, S. (eds.) the $4^{\text {th }}$ International Conference, Philadelphia, Pennsylvania, p. 1 (2009). doi: 10.1145/1555619.1555631

8. March, S.T., Smith, G.F.: Design and natural science research on information technology. Decision Support Systems (1995). doi: 10.1016/0167-9236(94)00041-2

9. Peffers, K., Tuunanen, T., Rothenberger, M.A., Chatterjee, S.: A Design Science Research Methodology for Information Systems Research. Journal of Management Information Systems (2007). doi: 10.2753/MIS0742-1222240302

10. Holmström, J., Ketokivi, M., Hameri, A.-P.: Bridging Practice and Theory. A Design Science Approach. Decision Sciences (2009). doi: 10.1111/j.1540-5915.2008.00221.X

11. Pries-Heje, J., Baskerville, R., Venable, J.: Strategies for design science research evaluation. ECIS 2008 proceedings, 1-12 (2008)

12. Gill, A.Q., Chew, E.K., Kricker, D., Bird, G.: Adaptive Enterprise Resilience Management. Adaptive Action Design Research in Financial Services Case Study. In: 2016 IEEE $18^{\text {th }}$ Conference on Business Informatics (CBI). 2016 IEEE $18^{\text {th }}$ Conference on Business Informatics (CBI), Paris, France, 29.08.2016 - 01.09.2016, pp. 113-122. IEEE (2016). doi: 10.1109/CBI.2016.21

13. Oyelere, S.S., Suhonen, J.: Design and Implementation of MobileEdu M-learning Application for Computing Education in Nigeria. A Design Research Approach. In: 2016 International Conference on Learning and Teaching in Computing and Engineering (LaTICE). 2016 International Conference on Learning and Teaching in Computing and 
Engineering (LaTICE), Mumbai, India, 31.03.2016 - 03.04.2016, pp. 27-31. IEEE (2016). doi: 10.1109/LaTiCE.2016.3

14. Keijzer-Broers, W., Florez-Atehortua, L., Reuver, M.d.: Prototyping a Health and Wellbeing Platform. An Action Design Research Approach. In: 2016 49 ${ }^{\text {th }}$ Hawaii International Conference on System Sciences (HICSS). $201649^{\text {th }}$ Hawaii International Conference on System Sciences (HICSS), Koloa, HI, USA, 05.01.2016 - 08.01.2016, pp. 3462-3471. IEEE (2016). doi: 10.1109/HICSS.2016.432

15. Crepon, R.: Application of design research methodology to a contex-sensitive study in engineering education. In: 2014 IEEE Frontiers in Education Conference (FIE) Proceedings. 2014 IEEE Frontiers in Education Conference (FIE), Madrid, Spain, 22.10.2014 - 25.10.2014, pp. 1-4. IEEE (2014). doi: 10.1109/FIE.2014.7044254

16. Eisenhardt, K.M.: Building Theories from Case Study Research. The Academy of Management Review 14(4), 532-550 (1989)

17. McAfee, A.: Enterprise 2.0. New collaborative tools for your organization's toughest challenges. Harvard Business Press, Boston, Mass. (2009)

18. Menzel, C.M.: Web 2.0 as approach for the enterprise information technology, Universität, Fak. III, Wirtschaftsinformatik (2007)

19. Back, A.: Enterprise 2.0 - Digitale Transformation durch soziale Technologien. In: Hoffmann, C.P., Lennerts, S., Schmitz, C., Stölzle, W., Uebernickel, F. (eds.) Business Innovation: Das St. Galler Modell, pp. 123-138. Springer Fachmedien Wiesbaden, Wiesbaden (2016)

20. Hinchcliffe, D., Kim, P.: Social business by design. Transformative social media strategies for the connected company. Jossey-Bass, A Wiley Imprint, San Francisco (2012)

21. Ellison, N.B., Gibbs, J.L., Weber, M.S.: The Use of Enterprise Social Network Sites for Knowledge Sharing in Distributed Organizations. The Role of Organizational Affordances. American Behavioral Scientist (2014). doi: 10.1177/0002764214540510

22. Ellison, N.B., Gibbs, J.L., Weber, M.S.: The use of enterprise social network sites for knowledge sharing in distributed organizations: The role of organizational affordances. American Behavioral Scientist 59(1), 103-123 (2015)

23. Mausz, N.: Enterprise Social Network. http://docplayer.org/2217553-Enterprise-socialnetwork.html (2012)

24. Büchner, T., Matthes, F., Neubert, C.: A Concept and Service based Analysis of Commercial and Open Source Enterprise 2.0 Tools. In: KMIS, pp. $37-45$ (2009)

25. McKinsey: Business and Web 2.0: An interactive feature. http://www.mckinsey.com/business-functions/digital-mckinsey/our-insights/businessand-web-20-an-interactive-feature (2013). Accessed 23 January 2017

26. Breuer, J., Bente, G.: Why so serious? On the relation of serious games and learning. Journal for Computer Game Culture 4, 7-24 (2010)

27. Garris, R., Ahlers, R., Driskell, J.E.: Games, Motivation, and Learning. A Research and Practice Model. Simulation \& Gaming (2002). doi: 10.1177/1046878102238607

28. Darejeh, A., Salim, S.S.: Gamification Solutions to Enhance Software User Engagement-A Systematic Review. International Journal of Human-Computer Interaction (2016). doi: 10.1080/10447318.2016.1183330

29. Bakhuys Roozeboom, M., Visschedijk, G., Oprins, E.: The effectiveness of three serious games measuring generic learning features. $\mathrm{Br} \mathrm{J}$ Educ Technol (2017). doi: $10.1111 /$ bjet. 12342 
30. Rasch, G.: Probabilistic models for some intelligence and attainment tests. Univ. of Chicago Pr, Chicago (1980)

31. Groth, D., Skandier, T.: Network+ study guide, $4^{\text {th }}$ edn. Sybex, Alameda, Calif. (2005) 